\title{
STATUS OF THE NIOBIUM RESONATOR CONSTRUCTION PROJECT FOR THE NEW DELHI BOOSTER LINAC
}

\author{
P.N.Potukuchi ${ }^{*}$ and S.Ghosh ${ }^{*}$ \\ Nuclear Science Centre, Aruna Asaf Ali Marg, New Delhi 110067, India \\ and \\ K.W.Shepard \\ Physics Division, Argonne National Laboratory, 9700 S. Cass Ave, Argonne, IL 60439, USA
}

\begin{abstract}
This paper reports the construction of niobium superconducting quarter wave resonant cavities for a booster linac for the 15 UD Pelletron accelerator at the Nuclear Science Centre. The resonators have been developed, and are being constructed, in collaboration with Argonne National Laboratory. Construction of the first batch of ten resonators started in May ' 97 and is expected to be completed by June ' 99 . The incremental cost is expected to be about $\$ 36 \mathrm{~K}$ per cavity. Status and details of construction, and results of the first cold test are presented.
\end{abstract}

\section{INTRODUCTION}

A superconducting linear accelerator booster for the existing 15 UD tandem Pelletron accelerator [1], at the Nuclear Science Centre, is presently being constructed in collaboration with Argonne National Laboratory (ANL). A prototype quarter wave resonator (QWR) was designed, fabricated and tested successfully at ANL [2]. The linac will eventually consist of three cryostat modules each containing eight QWRs [3]. A total of twenty seven cavities, including one for the superbuncher and two for the rebuncher, will be needed for the linac. Construction of the first batch of ten resonators is presently nearing completion at ANL [4].

Figure 1 shows a schematic diagram of the $97 \mathrm{MHz}$ quarter wave resonator optimised for a particle velocity $\beta$ $(=\mathrm{v} / \mathrm{c})=0.08$. Details of the cavity design have been presented elsewhere [5].

\section{PRODUCTION DETAILS}

The entire production is being carried out with commercial vendors in USA and India $[6,7,8]$, unlike the prototype development project which was done in-house at ANL. Before the production started the technology of fabricating niobium resonators was transferred to the vendors. Considerable time and effort went into training vendors to perform the machining and sheet metal work on niobium. Similarly, a major effort went into developing electron beam welding parameters for welding different thickness of niobium [9]. The electron beam welder is a five-axis CNC machine with movable gun and tilt, and a large vacuum chamber. The machine is equipped with a three head stock rotary fixture with matching tail stocks. To increase productivity, the entire weld fixturing was designed to perform multiple welds in a single pump down.

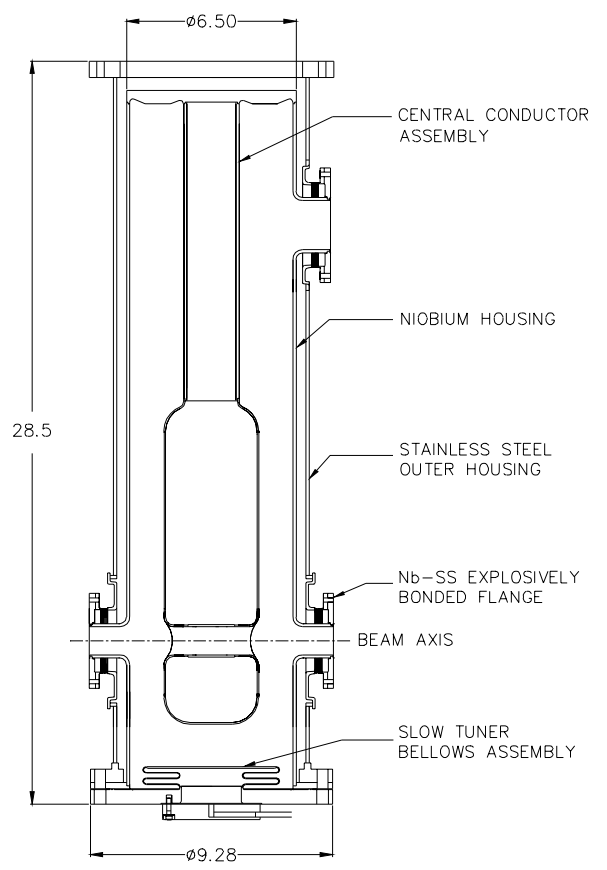

Figure 1: Schematic diagram of the $97 \mathrm{MHz}$ quarter wave coaxial-line cavity. Dimensions are in inches.

The contract for the first batch of production calls for fabricating ten resonators. Because of higher productivity from the electron beam welder, than anticipated, we will produce twelve complete resonators and most of the parts for two more. The entire fabrication effort has been done in several major groups of tasks [4].

* Currently at the Physics Division, Argonne National Laboratory, 9700 S. Cass Ave, Argonne, IL 60439, USA 


\section{PRESENT STATUS}

At the time of writing this paper all the major subassemblies of the resonators, except the slow tuner bellows, have been fabricated. This represents about $85 \%$ of the total machining \& sheet metal work, and about $66 \%$ of the total electron beam welding work for the project. Figures 2 and 3 show the bare niobium housings and the central conductor assemblies respectively.

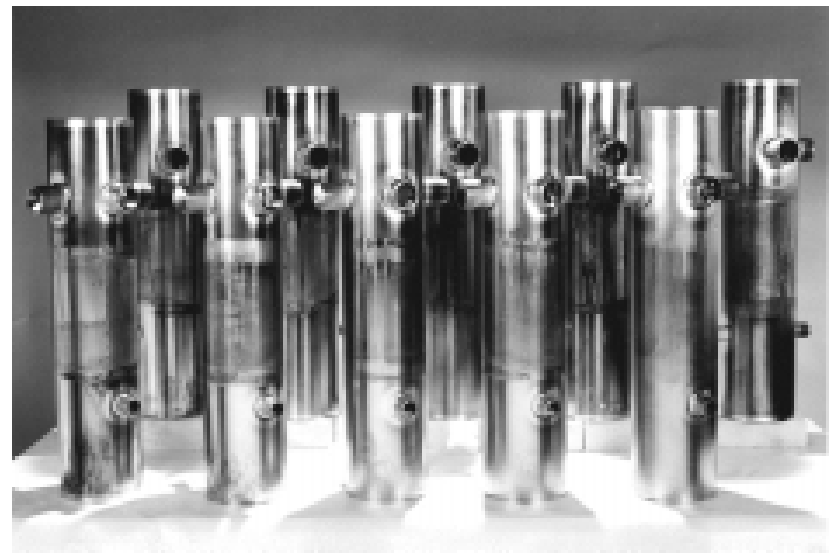

Figure 2: Niobium housings with the beam \& coupling ports.

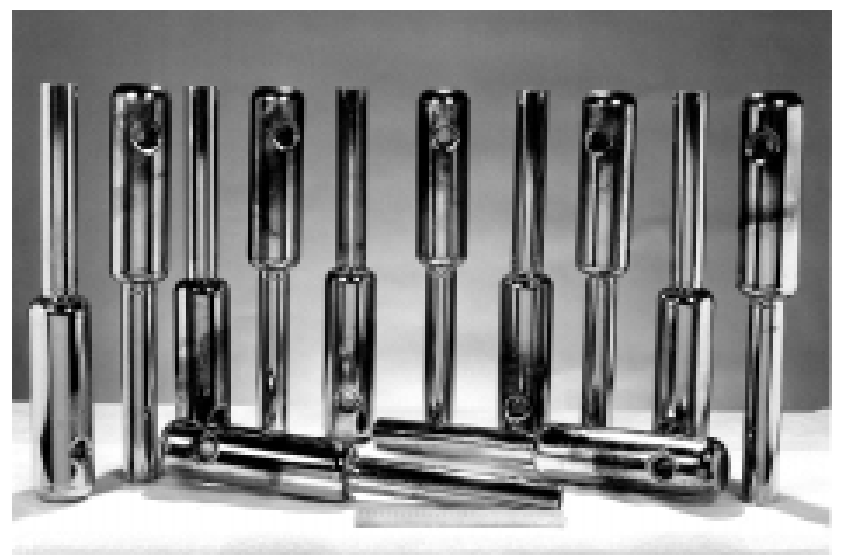

Figure 3: Niobium central conductor assemblies.

We have completed fabricating two resonators, which are being tested. Figure 4 shows the first two resonators complete with the stainless steel jackets. The remainder are $70 \%$ complete, they have been tuned to frequency and the central conductor assemblies are being prepared for welding to the top flange. The slow tuner fabrication work will start shortly.

\section{COLD TEST RESULTS}

The first resonator was recently tested (without the slow tuner bellows) at $4.5 \mathrm{~K}$ and performed as shown in figure 5 . The minimum performance goal of $3 \mathrm{MV} / \mathrm{m}$ with 4 watts of rf input power has been exceeded. The magnetic shielding in the test cryostat has been found to be inadequate, and the higher rf losses in the cavity are thought to be from trapped magnetic flux from earth's magnetic field. Magnetic shielding is now being put around the test cryostat.

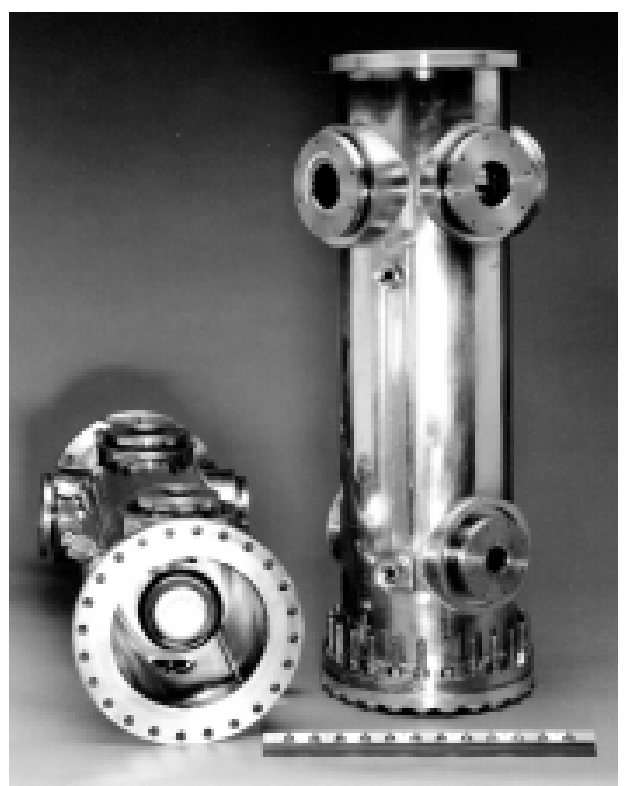

Figure 4: First two resonators complete with the stainless steel outer housings.

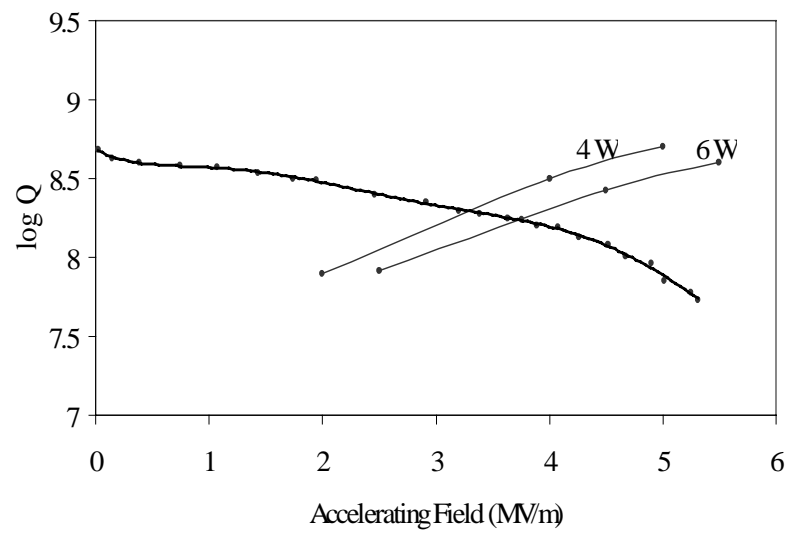

Figure 5: Resonator $\mathrm{Q}$ as a function of accelerating gradient at $4.5 \mathrm{~K}$

\section{COSTS AND EFFORT}

Figure 6 shows the niobium material, fabrication and electron beam welding cost for the project. Several points should be noted:

a) We are building twelve complete resonators and most of the parts for two more. We consider the effort to be equivalent to building thirteen resonators.

b) The costs indicated represent the incremental costs and do not include the cost of the tooling. Most of the tooling made during the prototype resonator 
development project has been used. However, additional tooling was made as felt needed.

c) The fabrication cost indicates the machining and sheet metal work on the niobium parts of the resonators. In addition to this cost, approximately 750 hours of effort was involved in fabricating the stainless steel parts at the vendor in reference 8 .

d) The cost of fabrication is about $\$ 60 / \mathrm{hr}$, and the cost of electron beam welding is $\$ 200 / \mathrm{hr}$.

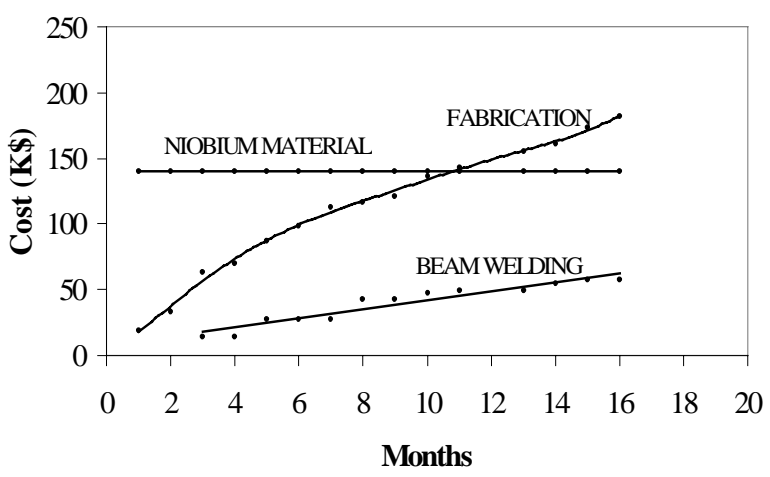

Figure 6: Production costs as a function of time. The entire work is expected to be completed before the end of the twentieth month.

e) The electropolishing and heat treatment of the niobium parts is being performed in-house at ANL. The resonator tests are also performed at ANL.

\section{CONCLUSIONS}

Production of the first batch of resonators for the New Delhi linac is nearing completion. Major sub-assemblies of all the resonators have been fabricated and the entire production work is expected to be completed by June ' 99 . Two cavities have been completed initially and the first resonator has performed above the nominal design goal. The incremental projected cost will be $\$ 36 \mathrm{~K}$ per cavity.

\section{ACKNOWLEDGEMENTS}

The authors would like thank Mr. Radwan Mourad and Mr. Tadeusz Hejna of Sciaky Inc., Mr. Edward Bonnema and Mr. Lester Dudek of Meyer Tool \& Mfg., Inc., and the staff of Don Bosco Technical Institute, for their help during this work. The authors would like to thank Mr. Mark Kedzie for his help and suggestions during the electron beam welding of the resonator parts. Thanks are due to Mr. Rajeev Mehta and Dr. Amit Roy for getting the stainless steel work, and the transition flange machining, done at New Delhi. The authors acknowledge the continuing support of Prof. G.K.Mehta, Dr. Jerry Nolen and Dr. Walter Henning during the project.

This work is performed at Argonne National Laboratory, and is funded by the Nuclear Science Centre, New Delhi by the University Grants Commission of the Government of India.

\section{REFERENCES}

[1] D.Kanjilal et al., Nucl. Instr. and Meth. A328 (1993), p97

[2] K.W.Shepard, A.Roy and P.N.Potukuchi, Proc. of the 1997 Particle Accelerator Conference, May 12-16, 1997, Vancouver, BC, Canada, p3072

[3] A.Roy et al. to be published in the Proc. of the $8^{\text {th }}$ International Conference on Heavy Ion Accelerator Technology, October 5-9, 1998, Argonne, IL, USA

[4] P.N.Potukuchi, S.Ghosh and K.W.Shepard, to be published in the Proc. of the $8^{\text {th }}$ International Conference on Heavy Ion Accelerator Technology, October 5-9, 1998, Argonne, IL, USA

[5] K.W.Shepard, A.Roy and P.N.Potukuchi, Proc. of the 1993 Particle Accelerator, May 17-20, 1993, Washington, DC, p1045

[6] Meyer Tool \& Mfg., Inc., 4601 Southwest Hwy., Oak Lawn, IL 60453, USA

[7] Sciaky Inc., 4915 W. $67^{\text {th }}$ street, Chicago, IL 60638, USA

[8] Don Bosco Technical Institute, Okhla Road, Jamia Nagar, New Delhi, 110025, India

[9] Mark Kedzie, ATLAS, Argonne National Laboratory, Private Communication 